\title{
Erratum to: Proper management of rheumatoid arthritis in Latin America. What the guidelines say?
}

\author{
Claiton V. Brenol ${ }^{1,2}$ • Jorge Ivan Gamez Nava ${ }^{3,4}$ • Enrique R. Soriano ${ }^{5,6}$
}

Published online: 8 September 2015

(C) International League of Associations for Rheumatology (ILAR) 2015

\section{Erratum to: Clin Rheumatol}

DOI 10.1007/s10067-015-3016-9

The original version of this article unfortunately contains an error in the name of one of the authors. The name Claiton Brenol should be presented as Claiton V. Brenol. The correct author name is now presented in the authorgroup and affiliation sections.

The online version of the original article can be found at http://dx.doi.org/ 10.1007/s10067-015-3016-9.

Enrique R. Soriano

enrique.soriano@hospitalitaliano.org.ar

1 Rheumatology Unit, Hospital de Clinicas de Porto Alegre, Rio Grande do Sul, Brazil

2 Faculdade de Medicina, Universidade Federal do Rio Grande do Sul, Rio Grande do Sul, Brazil

3 Unidad de Investigación en Epidemiologia Clínica, UMAE Hospital de Especialidades del Centro Médico Nacional de Occidente, Instituto Mexicano del Seguro Social, Guadalara, Mexico

4 Programas de Doctorado en Salud Publica y Farmacologia, Centro Universitario de Ciencias de la Salud, Universidad de Guadalajara, Guadalajara, Mexico

5 Rheumatology Unit, Internal Medicine Service, Hospital Italiano de Buenos Aires, Peron 4190, (1180), Buenos Aires CABA, Argentina

6 Instituto Universitario, Hospital Italiano de Buenos Aires, Peron 4190, (1180) Buenos Aires, CABA, Argentina 